\title{
FUNÇÃO HISTÓRICA DA CALIGRAFIA EM SARAMAGO
}

José Leite Jr. ${ }^{1}$

Resumo: O romance Manual de pintura e caligrafia, de José Saramago, estabelece um paralelo entre a história da escrita e o drama pessoal do protagonista. A análise semiótica permite perceber que o personagem principal toma consciência de sua condição de classe, opondo-se aos valores burgueses. Nesse romance, assim como ocorreu na humanidade, a passagem da pré-história à história corresponde à passagem da pintura à grafia. A caligrafia resulta de uma síntese dialética entre a pintura e a escrita e serve de metáfora ao desmascaramento ideológico.

Palavras-chave: romance de Saramago; literatura e pintura; semiótica discursiva; ideologia.

\section{HISTORICAL FUNCTION OF CALLIGRAPHY IN SARAMAGO}

Abstract: The novel Manual de pintura e caligrafia, by José Saramago, sketches a parallel between the history of writing and the personal drama of the protagonist. The semiotic analysis allows us to see that the main character becomes aware of their class status, was opposed to bourgeois values. In this novel, as occurred in humanity, the transition from prehistory to history corresponds to the passage from painting to graphy. The calligraphy is a dialectical synthesis between painting and writing and serves as a metaphor to the ideological unmasking.

Keywords: José Saramago's novel; literature and painting; discursive semiotics; ideology.

\section{Introdução}

O objetivo deste artigo é apresentar traços semióticos, pelos quais se configura o estilo maduro do escritor português José Saramago. Orientam nossa descrição sobre a relação entre a pintura artística e a literatura, no Manual de pintura e caligrafia ${ }^{2}$ (MPC), categorias semióticas propostas por Algirdas Julien Greimas, em articulação com a concepção marxista de ideologia. A propósito desta dupla visada epistemológica para o exame da linguagem literária, é oportuno lembrar que, para o linguista e semioticista Fiorin, que retoma Marx e Engels de $A$ ideologia alemã :

A linguagem é um fenômeno extremamente complexo, que pode ser estudado de múltiplos pontos de vista, pois pertence a diferentes domínios. É, ao mesmo tempo, individual e social, física, fisiológica e psíquica. Por isso, dizer que a linguagem sofre determinações sociais e também goza de uma certa autonomia em relação às formações sociais não é uma contradição. (FIORIN, 1998, p. 8-9)

E esse mesmo semioticista greimasiano afirma que a ideologia se revela no nível

1 José Leite de Oliveira Junior, doutor em Letras pela UFPB, integrante do quadro permanente do Programa de Pós-Graduação em Letras da UFC.

2 A primeira edição foi publicada em 1977. Para este artigo foi consultada a seguinte edição: SARAMAGO, José. Manual de pintura e caligrafia. Porto: Lello \& Irmão, 1991. 


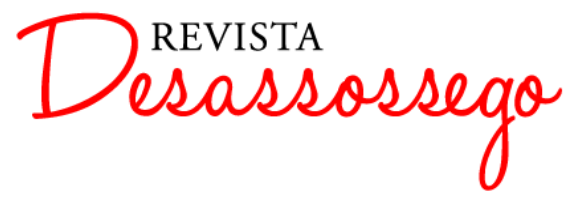

DESASSOSSEGO 13 | JUN/2015 | ISSN 2175-3180

DOI: http://dx.doi.org/10.11606/issn.2175-3180.v7i13p55-68

discursivo da produção do sentido de um texto:

\begin{abstract}
Uma formação ideológica deve ser entendida como a visão de mundo de uma determinada classe social, isto é, um conjunto de representações, de ideias que revelam a compreensão que uma dada classe tem do mundo. Como não existem ideias fora dos quadros da linguagem, entendida no seu sentido amplo de instrumento de comunicação verbal ou não-verbal, essa visão de mundo não existe desvinculada da linguagem. Por isso, a cada formação ideológica corresponde uma formação discursiva, que é um conjunto de temas e de figuras que materializa uma dada visão de mundo. (FIORIN, 1998, p. 33)
\end{abstract}

Sabe-se que o MPC abre a fase literária em que José Saramago firmou-se como ficcionista. Antes desse romance, cuja primeira edição data de 1977, já existiam, ainda que dispersas em obras distintas, invariantes que confluiriam para o estilo maduro do romancista. Fato, aliás, reconhecido pelo próprio Saramago (1991b, p. 5), ao afirmar que "nexos, temas e obsessões", já presentes em sua obra poética, constituiriam a "coluna vertebral, estruturalmente invariável, de um corpo literário em mudança”.

Não há como negar uma relação congruente entre o Saramago anterior e o outro, que se mostraria desde 1977. No entanto, merece reconhecimento a superior qualidade desse romance, que retomou elementos poéticos, dramáticos e jornalísticos até então esboçados para os superar esteticamente num verdadeiro salto dialético. É poético o refinamento experimental do arranjo frasal, é teatral o monólogo e o diálogo inseridos no texto ficcional e é jornalística a missão histórica, tomada para si pelo autor como crítica radical à sociedade fundada sobre os valores do capitalismo, sobretudo em sua fase neoliberal.

\title{
Semiótica da missão revolucionária
}

A práxis marxista não foi esquecida pelo atento Greimas (1973, p. 237), que assim resume a teleologia da revolução:
Sujeito Ser humano
Objeto Sociedade sem classes sociais
Destinador História
Destinatário Humanidade
Oponente Burguesia
Coadjuvante Classe trabalhadora

Greimas observa o mundo social como texto. O esquema acima traz o corte do 
nível narrativo do percurso gerativo do sentido. O marxista, segundo esse esquema actancial, figurativiza o sujeito que assume contratualmente sua destinação histórica, já que quer e se sente no dever de construir a sociedade comunista, quando haveria a superação da exploração do homem pelo homem e a abolição das classes sociais.

Saramago não esconde que é marxista. Assim, sua obra se apresenta como testemunho intelectual para a construção de uma alternativa ideológica ao modelo burguês de sociedade. Seu texto funciona como modalizador do saber necessário ao desmascaramento do antissujeito figurativizado pela burguesia e seus valores ideologicamente legitimados. Tal missão, como mostra o esquema acima, lhe confere a história humana, cuja marcha é movida pela luta de classes. Cabe lembrar que a mesma história sincretiza o actante destinador-manipulador, que faz o pacto revolucionário com o intelectual e o actante destinador-julgador, que sanciona o desempenho do ator revolucionário (julgamento histórico).

Merece atenção o fato de que em geral a classe revolucionária é apenas potencial ou hipoteticamente propensa à revolução, visto que ela normalmente não dispõe de um suficiente conhecimento teórico sobre si mesma. Não por acaso Greimas identifica a classe trabalhadora como coadjuvante da missão histórica. As condições de vida do proletariado não o fazem "naturalmente" capaz de destituir o domínio burguês sobre o Estado, por mais que o proletariado seja o maior beneficiário de uma revolução que venha abolir a propriedade privada dos meios de produção. Miséria, enfim, não faz revolução. Segundo o entendimento marxista, o miserável tende inclusive a traí-la: "Por toda sua situação de vida, ele [o lumpemproletariado] tende a ser subornado para intrigas reacionárias" (MARX; ENGELS, 1990, p. 48). Em consequência disso, o proletariado precisaria aprender com o intelectual revolucionário acerca do próprio papel histórico. Esse conhecimento sobre o lado correto a ser tomado no antagonismo histórico representa o pressuposto subjetivo da revolução social. Enfim, é a cultura revolucionária que prepara a revolução socioeconômica. Semioticamente falando, o intelectual aqui tratado opera como o coadjuvante que atribui a competência cognitiva (saber revolucionário), sem a qual a competência pragmática (fazer revolucionário) seria infrutífera ao propósito histórico da classe potencialmente revolucionária.

No MPC, o protagonista metonimicamente (GREIMAS; COURTES, 2008, p. 311312) assume o papel do sujeito histórico, ou seja, o que recebeu a destinação histórica. 
Dissemos "metonimicamente", pois o enquadramento individual do romance representa, em escala menor, a sociedade onde se encontra o protagonista, artista que vive os últimos dias da ditadura em Portugal (Salazarismo, 1933-1974). A intenção não é, nos limites desse romance, diretamente abolir as classes sociais, porém, certamente, construir uma ferramenta especulativa ou um discurso que ensaia o desvelamento da ideologia burguesa. Essa voz discordante (do intelectual), em combate com as vozes que repisam o discurso ideológico, vem metaforizada em inúmeros trechos do MPC, como neste exemplo:

Digo coisas que todos dizem, mas este feltro pisado e repisado que é a cultura, que é a ideologia, que é também isso a que chamamos civilização, compõe-se de mil e um pequenos estilhaços, que são heranças, vozes, superstições que foram e assim permaneceram, convicções que esse nome se dão e tanto lhes basta (MPC, p. 733)

O protagonista do MPC é um medíocre pintor de retratos. Pessoas que desejam eternizar-se por esse expediente formam a clientela do pintor. $\mathrm{Na}$ sequência dos episódios, o cliente, denominado pela letra S., metonimicamente desempenha o papel de comprador da força de trabalho do artista, por sua vez figura dessacralizada no mundo burguês (MARX; ENGELS, 1990, p. 37). Quanto ao desejo de se eternizar pela obra artística, a burguesia o herdou da extinta classe social aristocrática.

A consciência de semelhante idolatria adaptada ao modo de viver burguês não escapa ao pintor-personagem, que, procurando produzir uma obra pela escrita, cita como argumento de autoridade, entre outros, a obra-prima de Erasmo de Roterdã. Segundo o pintor,

não é raro que o modelo tenha a preocupação de parecer-se com o retrato, se este o fixou no relance em que o ser humano se louva e aceita. Vive o pintor para surpreender esse relance, vive o modelo para o instante que será o pilar pessoal e único dos dois ramos de uma eternidade que vem transitando infinitamente e que, algumas vezes, a loucura humana (Erasmo) julga poder assinalar com um pequeníssimo nó, uma excrescência capaz de arranhar esse dedo gigantesco com que o tempo apaga todos os vestígios. (MPC, p. 641)

Ao decidir-se pela escrita, o pintor experimenta desmascarar a intenção ideológica subjacente aos retratos elaborados por encomenda, ou seja, nega o parecer (como a ideologia se manifesta) e afirma o ser (como a ideologia é em sua imanência). No caso acima ilustrado, o modelo insiste na construção de seu simulacro, contando para isso com a cooptação do artista, mas é o tempo - por que não dizer a história - que revelará a imanência humana ideologicamente escamoteada por essa dissimulação estética. 
Paradoxalmente, quanto mais parecido é o retrato, mais a obra dissimula o jogo opressivo que a compõe. Ser pintor de uma pretensa eternidade individual significaria, pois, ser um colaboracionista.

Especulando não por sua costumeira arte, mas por escrito, o protagonista tenta vencer essa microscópica (metonímica) versão da luta de classes: "Que quero eu? Primeiramente, não ser derrotado. Depois, se possível, vencer.” (MPC, p. 647) No entanto, a ideologia é sutil, e o método simbólico para o desmontar é um saber que o pintor ainda não possui, até pelo fato de que a serviçal pintura de retratos, simples cópia do modelo, não o aprovisiona de um instrumental especulativo para tal fim. Por isso ele hesita quanto ao caminho que tomará: "Não sei que passos darei, não sei que espécie de verdade busco: apenas sei que se me tornou intolerável não saber.” (MPC, p. 647) Ele ainda não sabe exatamente o que fazer, mas já é movido por uma crença. Tem, pois, um saber epistêmico que o faz avaliar negativamente sua práxis (autocrítica) e redirecionar seu percurso em busca de uma verdade apenas vislumbrada.

Para melhor analisar o oponente de classe social, ou seja, o senhor S., o pintor se faz escritor. Essa decisão figurativamente se apresenta como um ensaio crítico sobre a classe burguesa. Pormenores como a vantagem de berço da classe burguesa e a inerente exploração da força de trabalho dos "invisíveis combatentes" não faltam nesse estudo. Notável é metáfora da reificação conferida aos adjuvantes do antissujeito:

Dir-se-ia que nasceu já com todas as batalhas ganhas ou que dispõe, para lutarem em seu lugar, de invisíveis combatentes que vão morrendo cuidadosamente, sem ruído, sem eloquência, alisando o caminho, como se eles próprios fossem simples ramagens de vassoura. (MPC, p. 649)

A luta entre o pintor e o modelo (burguês) desenvolve-se em segredo. Exemplifica essa querela silenciosa a ocasião, quando S. pega um cigarro, mas o pintor não usa seu isqueiro para mostra-se gentil ao cliente:

S. teria gostado que eu lhe reconhecesse o dinheiro que tem e o poder que lhe adivinho. Contudo, os artistas praticam por tradição alguns privilégios que mesmo quando não usam ou usam ao invés mantêm uma aura romântica de irreverência que confirma o cliente na sua (provisória) condição subalterna e na sua particular superioridade. Nessa relação, algo teatral, cada um representa o seu papel. No fundo, S. ter-me-ia desprezado se eu the acendesse o cigarro, mas, muito pior do que isso, teria ficado logrado se eu o tivesse feito. Não houve surpresas para nenhum dos lados, e tudo se passou como convinha. (MPC, p.650)

Nesse jogo teatral, o protagonista estuda o oponente. Não escapa da parte do 


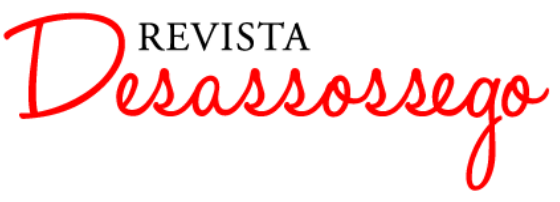

observador a aparência de superioridade do chamado charme da burguesia. Sujeito e antissujeito, aí figurativizados, disputam um mesmo objeto-valor, tematizado pelo poder, disfarçado por gestos de gentileza e elegância. Para um, o tema do poder ganha a figura da "aura romântica de irreverência"; para o outro, a reiteração das posições hierárquicas ritualizadas pelas regras de etiqueta.

Livre do pincel, pintor de palavras tem a liberdade de compor um retrato de S. segundo o estereótipo plasmado pela indústria norte-americana de cinema:

Tem, em suma, a orografia de rosto que os homens ambicionam porque o cinema americano a divulgou e porque a ela se liga um certo tipo de mulheres de cabelos longos, mas que talvez não valha a pena conservar (o rosto, não as mulheres) por mais tempo do que o «flash» fotográfico: porque a vida é muito mais feita de banalidade, de palidez, de barba mal rapada ou mal crescida, de hálito sem frescura, de cheiro de corpo nem sempre lavado. (MPC, p.651)

O pintor, ciente de que a vida real tem outras formas figurais, busca desvendar a verdade sob a máscara cinematográfica do oponente. $O$ quadrado veriditório abaixo (GREIMAS; COURTES, 2008, p. 532) esclarece a relação entre "ser" e "parecer", que encontramos nesse jogo, em que não explicitamente atuam rivais ideológicos:

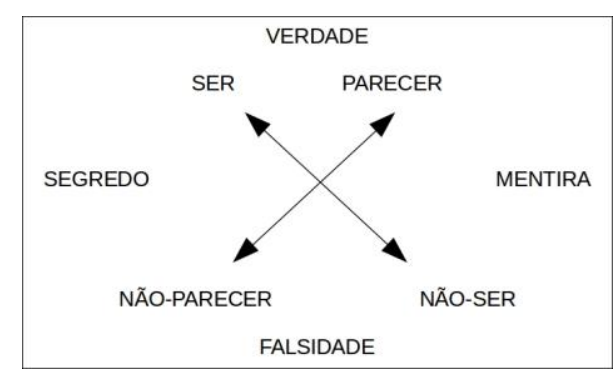

Figura 1: Quadrado veriditório de Greimas.

Descobrir a verdade, neste caso, é negar o que aparenta sobre S. e afirmar o ser sob S. Sobre S. está sua máscara ideológica. Sob S. está o humano vulgar, banal, sem o brilho dos flashes, com barba por fazer, comum e existencialmente fragilizado. No entanto, a ideologia se apresenta como algo que parece, mas não é; em outras palavras, como mentira (não-ser + parecer $=>$ mentira). Por sua vez, o pintor não deve revelar seu objetivo de desmascarar o antagonista; então também ele não parece tal qual verdadeiramente é, ou seja, como intérprete ou crítico do status burguês, mantendo-se estrategicamente em segredo (não-parecer + ser $=>$ segredo).

O que esse jogo de aparências ilustra é que a luta de classes nem sempre se opera 
num cenário de campo de batalha. Não é outra a constatação de Marx e Engels no mais popular de seus escritos:

Homem livre e escravo, patrício e plebeu, barão e servo, mestre e aprendiz, em suma, opressores e oprimidos, mantiveram-se um contra o outro em duradora oposição, tiveram uma luta ininterrupta, às vezes disfaçada, às vezes aberta, luta, que sempre terminava em transformação revolucionária de toda a sociedade ou pelo perecimento comum das classes em contenda. (1990, p. 35-36).

Mas como aprofundar a crítica em pinturas de encomenda, que ilustram e reiteram valores burgueses? Evidentemente, o sujeito histórico deve equipar-se para essa luta. Por isso a escrita substitui a pintura como ferramenta especulativa para o desvendamento dos simulacros ideológicos. Semioticamente falando, a escrita funciona como um modalizador da competência cognitiva dessa experiência de desvelamento. A pintura, ao possibilitar a cópia do modelo, pelo retrato de encomenda, acabava por reproduzir o modelo ideológico que lhe é subjacente; já a escrita, ao recusar a cópia, dá ao sujeito as condições de construção do saber necessário à sua conjunção com o objeto-valor que o inquieta: a imanência.

\section{Sujeito histórico entre a pintura e a escrita}

No MPC, o privilégio especulativo da escrita permite entrever o conceito do autor a respeito da função da literatura na história humana. De fato, graças à escrita é que existe a história; e tudo leva a crer que é por aquela que é possível dar nova direção a esta última. A história surge pela escrita como um sintagma em moto perpetuo, tudo bem; mas também é pela escrita e não por outro meio que o sujeito histórico, inferindo o paradigma histórico, torna-se competente para alterar o sistema social, reescrevendo, assim, a própria história. Trata-se de uma operação de sincretismo actancial: o destinador-manipulador (história) e o sujeito (histórico) passam a não se diferenciar (conscientização). Ora, se negar a história significa negar a escrita, negar a literatura, que é a mais refinada manifestação da escrita, pode significar favorecer a barbárie. Uma forma particular de negar a literatura é reduzi-la à condição de mercadoria e o trabalho intelectual, à robótica venda da força de trabalho (MARX; ENGELS, 1990, p.37).

No MPC, desenvolve-se um ensaio ficcional, com que se examina a pintura e a literatura como meios de efetivação do trabalho intelectual. $\mathrm{O}$ artista se sente cansado da condição de pintor de retratos por encomenda. Como se viu, ele entedia-se ante a constatação de que se dedica a um trabalho infrutífero, constituído de pinturas vazias de 


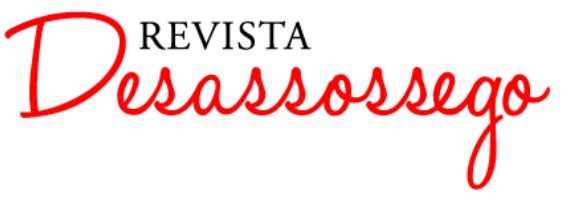

DESASSOSSEGO 13 | JUN/2015 | ISSN 2175-3180

DOI: http://dx.doi.org/10.11606/issn.2175-3180.v7i13p55-68

substância própria, sem discurso próprio, visto que são meras cópias escravas do objeto.

O pintor cai em profunda crise. A simples cópia do objeto por dinheiro não só nega o caráter intelectual do trabalho artístico como também reduz a obra à simples mercadoria. Essa percepção crítica inicialmente instiga o pintor a fazer uma nova pintura de S., trabalho composto secretamente. Talvez por um novo estilo ele fosse capaz de criar uma metalíngua pictórica, pela qual seria possível resolver o problema da alienação do trabalho intelectual. Mas cedo ele capitula:

Continuarei a pintar o segundo quadro, mas sei que nunca o acabarei. A tentativa falhou, e não há melhor prova dessa derrota, ou falhanço, ou impossibilidade, do que a folha de papel em que começo a escrever (...). (MPC, p. 637).

Observado o problema por um prisma semiótico, admite-se que a imagem fotografada, pintada ou desenhada tenha certa conotação (Barthes, 1990, 27-43). Curiosamente, o mimetismo que vem sendo potencializado pela tecnologia não revela, mas efetivamente disfarça o que se passa no plano do significado. Quem o afirma é Barthes, que, não tendo conhecido a revolução digital que estamos vivendo, parece profetizar:

É, sem dúvida, um importante paradoxo histórico: quanto mais a técnica desenvolve a difusão das informações (especialmente das imagens), mais fornece meios de mascarar o sentido construído sob a aparência do sentido original. (1990, p. 37)

Por mais que admita que um desenho tenha mais conotação do que uma fotografia, Barthes afirma que a imagem é polissêmica por excelência. Daí os dois papéis que ele atribui ao texto linguístico em relação à imagem: o de fixação e o de relais (1990, p. 32). O texto que aparece sob uma fotografia de jornal é exemplo de fixação, ou seja, o nome de uma pessoa sob sua imagem fotografada afasta toda uma gama de conotações (comerciais, antropológicas, estéticas, etc.). O diálogo que aparece numa história em quadrinhos é exemplo de relais, visto que estabelece um sentido de continuidade entre o quadro anterior e o subsequente. A imagem, enfim, mais sugere a discussão que propriamente discute algo.

Essa negação da pintura, que se configura no caso individual do pintorpersonagem, no MPC, vemo-la como metonímia de um longo percurso histórico.

Milhares de anos atrás, a pintura rupestre, ao que tudo indica, funcionava como magia. Pela pintura, o homem pré-histórico sentia-se capaz de influir no mundo natural. Reproduzir a imagem do animal selvagem, por exemplo, significava ter um domínio sobrenatural sobre ele. Semioticamente vista, tal função mágica da arte é exemplo de 


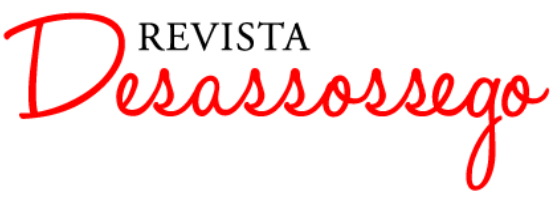

DESASSOSSEGO 13 | JUN/2015 | ISSN 2175-3180

DOI: http://dx.doi.org/10.11606/issn.2175-3180.v7i13p55-68

asserção da cultura na dicotomia natureza-cultura (GREIMAS; COURTES, 2008, p. $522-$ 524). Se o caos do mundo natural (de acordo com a compreensão semiótica) domina a cultura, pela arte mágica (símbolo) e pelos artefatos (armas e outras instrumentos), o ser humano pré-histórico, pelo menos em certo grau, controlou a força da natureza.

Semioticamente a pintura e a escrita são formas culturais, que "negam" a natureza:

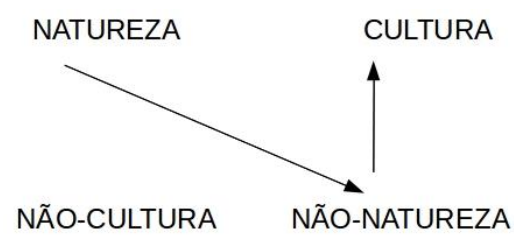

Figura 2: Negação da natureza em favor da cultura.

No MPC, o chamado da história (destinador-manipulador) surge na mente do protagonista como uma tomada de consciência (querer e dever fazer). Sentindo que a era dos cavernícolas não se extinguiu por inteiro, o protagonista-pintor incomoda-se com as sombras ancestrais que se atualizam. Escrever, para ele, é resgatar as pessoas que vivem à margem da história, fazendo-as constar no texto escrito:

A pré-história é longa, longa, andam por aqui homens e mulheres entrando e saindo de cavernas e é preciso fazer a história que os há-de contar (enumerá-los, narrá-los). Já os dedos inconscientes contam no sonho. Os números são letras. É a história. (MPC, p. 799)

Números e letras repartem a inauguração da história, quando, na sociedade escravista, por excedente de grãos, surgiu o comércio. Então, a ancestral pintura desenvolveu grafismos mais abstratos, servindo ao controle de mercadorias e de tributos: "Oitenta e cinco por cento das tábuas de argila de Uruk têm relação com o controle de alimentos, gado e tecidos" (MAN, 2002, p. 39).

De um modo geral, na Ásia Ocidental assim se deu a transformação da pintura em escrita, nomeadamente a pintura analógica (MAN, 2002):

pictograma $>$ ideograma $>$ silabograma $>$ fonograma

Assim como ocorreu com o pintor-protagonista do MPC, o ser humano teve que dominar a escrita para melhor controlar os afazeres sociais. Longe de imaginar um vínculo explícito do texto de Saramago como o de Jean Piaget, por outro lado fica difícil não observar que no MPC a ontogênese parece recapitular a filogênese, ou seja, o pintor 


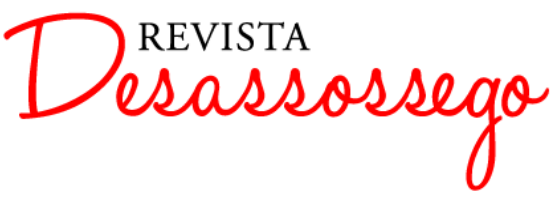

DESASSOSSEGO 13 | JUN/2015 | ISSN 2175-3180

DOI: http://dx.doi.org/10.11606/issn.2175-3180.v7i13p55-68

atualiza, em sua caverna-ateliê - que passa a escritório - o percurso que transformou o pintor rupestre no escriba. A projeção da filogênese (espécie) na formação cognitiva da ontogênese (indivíduo) é o que ensina Lauro de Oliveira Lima, criador do método psicogenético, baseado na pesquisa piagetiana (LIMA, 1980, p. 131), cuja proposta pedagógica respeita as etapas cognitivas do indivíduo.

Dito de outra forma, fazendo abstrações da pintura e superando a analogia direta com a natureza, o ser humano pragmática e graficamente criou a história. Mais do que magicamente tomar da natureza para simbolicamente a dominar, como se operou pela primitiva pintura, a escrita, tendo em si letras e números, possibilitou ao ser humano não só reinventar a natureza, por exemplo, mediante a arquitetura e engenharia, mas também replanejar e controlar a própria cultura por meio do direito, da política e da instrução. Exemplifica um dos primeiros controles jurídicos pela escrita o complexo código de Hamurabi ${ }^{3}$, contendo 247 artigos, e posteriormente, com mais abstração e síntese, os dez artigos do código de Moisés.

Nas sociedades antigas, tanto a pintura como a escrita significavam uma destinação divina (e, ainda atualmente, menciona-se Deus em muitas constituições). O destinatário era o ser humano e o objeto era a escrita (lei). O sujeito era o governante (rei), que tinha como apoio os aparatos jurídicos e políticos, e tudo se organizava conforme à concernente ideologia. No entanto, em desfavor dessa harmonia social vale lembrar as ameaças do instinto (a natureza contra o costume) e a crise social (catástrofe da natureza). O seguinte esquema semiótico (GREIMAS, 1973, p. 236) resume os termos dessa destinação:

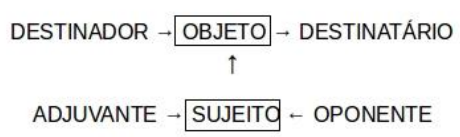

Figura 3: Esquema sobre a destinação de Greimas.

Dentre as sociedades antigas da Ásia Ocidental, aquela que mais radicalmente transitou da imagem para a escrita foi a hebreia (MAN, 2002). As leis de Moisés, apesar da influência da cultura do Egito ou até mesmo por esse fato, proibiram com rigor a pintura e a escultura:

3 Não terás outros deuses diante de mim. 4 Não farás para ti imagem de

3 http://www.louvre.fr/oeuvre-notices/code-de-hammurabi-roi-de-babylone 
escultura, nem alguma semelhança do que há em cima nos céus, nem em baixo na terra, nem nas águas debaixo da terra. 5 Não te encurvarás a elas nem as servirás; porque eu, o Senhor teu Deus, sou Deus zeloso, que visito a iniquidade dos pais nos filhos, até a terceira e quarta geração daqueles que me odeiam. $6 \mathrm{E}$ faço misericórdia a milhares dos que me amam e aos que guardam os meus mandamentos. (Êxodo 20:3-6)

Em decorrência dessa proibição, as considerações sobre Deus deveriam ser representadas somente pela palavra, de preferência a forma escrita da palavra (Bíblia), do que resulta que a escrita teve mais valorização do que a pintura entre o povo hebreu e, por extensão, no Ocidente, pela influência judaica ou neojudaica (cristã). Dessa matriz alfabética, que confirma a cultura e recusa a natureza, à qual afluiriam os códigos gregos e romanos, ergueu-se uma parte significativa da cultura ocidental.

$\mathrm{Na}$ atualidade não surpreende dizer que um pintor é um intelectual. Mas nem sempre foi assim. A pintura medieval geralmente se apresentava como resultado de trabalho corporativo guiado por um mestre. Antes do Renascimento, um pintor ainda não desfrutava do status de intelectual, mas de trabalhador manual. O ponto de virada, a esse respeito, se explica pela influência de artistas como Leonardo da Vinci e pela reconsideração sobre a função da pintura, a partir de então vista como texto narrativo segundo a cogitação: se a pintura narra algo descritivamente, então se trata de um texto (LICHTEINSTEIN, 2005, p. 12-13).

\section{Conclusão: a caligrafia revolucionária do manual}

Retornando ao pintor-protagonista do MPC, evidencia-se que ele, tocado por uma crise de criação, mudou o instrumento especulativo para cumprir sua destinação histórica. Para ele, a pintura tem limitação, no tocante ao discurso, ao passo que a escrita permite uma expressão ilimitada:

O meu trabalho vai agora ser outro: descobrir tudo da vida de S. e tudo relatar por escrito, distinguir entre o que é verdade de dentro e pele luzidia, entre a essência e a fossa, entre a unha tratada e a apara caída da mesma unha, entre a pupila azul-baço e a secreção seca que o espelho matinal denuncia no canto do olho. Separar, dividir, confrontar, compreender. Perceber. Exactamente o que não pude alcançar nunca enquanto pintei. (MPC, p. 652-653)

Para o pintor do MPC, transitar do retrato de encomenda para a escrita crítica significou, de algum modo, radicalmente abdicar da descrição passiva da natureza para fazer-se ativo protagonista da história humana: 


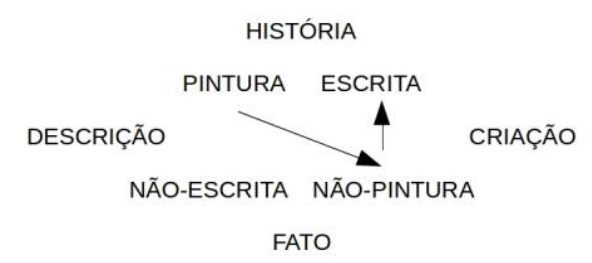

Figura 4: Negação da pintura e asserção da escrita.

Como mostra o esquema acima, tanto a pintura como a escrita estão relacionadas com a história. No entanto, se o sujeito histórico confirma a pintura e nega a escrita, essa escolha significa que ele descreve passivamente a história. Contrariamente, se ele nega a pintura e confirma a escrita, como fez o pintor-protagonista, isso quer dizer que ele tem à sua mão a possibilidade de recriar a história:

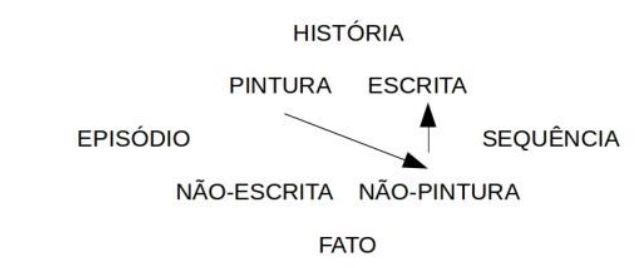

Figura 5: A pintura é paradigmática (episódica); a escrita é sintagmática (sequencial).

Outra característica da escrita que merece atenção é a possibilidade de ligar a sucessão dos fatos e ao mesmo tempo aprofundar a análise psicológica dos atores neles envolvidos. Embora pela pintura seja possível fixar o momento, nela dificilmente seria cabível captar a sucessão dos fatos. Pelo fato de a sucessão histórica ser sintagmática, tal caráter é mais possível captar pela escrita, que também se organiza segundo a sucessão e assim permite uma consideração mais profunda sobre os processos ficcionais ou reais.

Sendo sintagmática, a escrita representa, por sua sucessividade, o percurso do indivíduo (entre vida e morte) e da sociedade (entre cultura e natureza). Sendo paradigmática, a pintura fixa o indivíduo num episódio particular da sucessão histórica.

Somente a escrita se constitui como um discurso com valor legal, pelo qual seria possível estabelecer uma ordem social e também reestruturar essa mesma ordem, segundo dada destinação histórica. Tal dialética, consistindo nesse construir e reconstruir a ordem social, não fica fora das considerações íntimas do pintor-escritor:

Tentei destruir este homem quando o pintava, e descobri que não sei destruir. Escrever, não é outra tentativa de destruição, mas antes a 
tentativa de reconstruir tudo pelo lado de dentro, medindo e pesando todas as engrenagens, as rodas dentadas, aferindo os eixos milimetricamente, examinando o oscilar silencioso das molas e a vibração rítmica das moléculas no interior dos aços. (MPC, p. 651-652)

Alegoricamente, Saramago apresenta o processo da conscientização individual, cuja culminância é a libertação do estado de alienação. Nas entrelinhas, é possível captar aí uma representação da teleologia marxista. Efetivamente, não há verdadeira revolução se se perde o seu fim humanista, a imanência humana, valor revolucionário que, ressalte-se, é claramente textualizado no trecho acima, no propósito de se "reconstruir tudo pelo lado de dentro". Expropriar a classe burguesa do poder do Estado não se reduz a uma crua ação destruidora decorrente de um processo revolucionário abrupto ou prolongado. Mais certo, o eco revolucionário que ressoa das entrelinhas do MPC em essência propõe a vitória do argumento cultural por sobre a chamada lei natural ou lei da selva (liberalismo).

\section{Porém resta uma última questão: será que a pintura tem papel revolucionário?}

A pintura é a base sobre a qual se formou a escrita. O pintor tem seu lugar ao lado do escritor na tarefa comum de desmascarar a ideologia: nesse sentido, importa que o pintor nem proponha uma mistificação aos crédulos, pela idolatria (ideologia), nem tente fazer da pintura um discurso. Não compete à pintura a análise exaustiva, mas ao texto. Seu papel é captar o episódio para o ligar à dimensão histórica. Fixando o momento histórico, a imagem pintada certamente evocará o discurso. E não foi assim que fez, por exemplo, Pablo Picasso com sua Guernica ${ }^{4}$ ? Essa pintura, sem usar a palavra para suscitar uma tragédia histórica, certamente conclama um profundo debate. É silenciosa, mas capta o grito de dor, exigindo um posicionamento do sujeito histórico.

Por esta análise, não intentamos subestimar o papel do pintor, mas sondar o ponto de vista de Saramago a respeito das funções discursivas da pintura e da literatura no romance MPC. Com efeito, a escrita textualiza, mas a pintura pretextualiza.

Por isso as mais louváveis obras literárias são aquelas nas quais não se perde totalmente a ligação original com a pintura. Quanto mais rico é o romance, mais ele pinta, com o uso de palavras, inesquecíveis cenas sobre a tela mental do leitor.

Ora, o texto reconciliado com a pintura se chama caligrafia, na acepção de palavra

4 http://www.museoreinasofia.es/co1eccion/autores-obras.html?id=322 


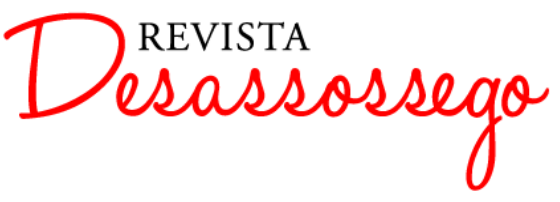

DESASSOSSEGO 13 | JUN/2015 | ISSN 2175-3180

DOI: http://dx.doi.org/10.11606/issn.2175-3180.v7i13p55-68

pintada, poeticamente refinada. A caligrafia é a forma de expressão pela qual Saramago, sobretudo desde o MPC, reinventa, em síntese, a poesia, o teatro e a crônica jornalística da fase anterior.

Como é possível depreender de Saramago no MPC, é função da escrita estabelecer o discurso histórico; é função da pintura atualizar o pré-histórico poder de, mágica ou culturalmente, interligar ser humano e natureza; mas é função da caligrafia sintetizar dialeticamente essas duas formas de expressão, para que a vida humana se depare sempre com uma nova imagem ao longo da história.

\section{Referências}

BARTHES, Roland. "A retórica da imagem”. In: O óbvio e o obtuso. Trad. Lea Novaes. Rio de Janeiro: Nova Fronteira, 1990.

BIBLIO. Trad. Lazaro Ludoviko Zamenhof (Malnova Testamento); Rust Berveling; Wilkinson Beveridge (Nova Testamento). Londres: British and Foreign Bible Society, 2003. FIORIN, José Luiz. Linguagem e ideologia. 6.ed. São Paulo: Ática, 1998.

GREIMAS, Algirdas Julien. Semântica estrutural. Trad. Haquira Osakabe e Izidoro Blikstein. São Paulo: Cultrix, 1973.

GREIMAS, Algirdas Julien; COURTÉS, Joseph. Dicionário de semiótica. Trad. Alceu Dias. Lima at al. São Paulo: Contexto, 2008.

LICHTEINSTEIN, Jacqueline (org.). A pintura: o paralelo das artes. São Paulo: Ed. 34, 2005. v.7.

LIMA, Lauro de Oliveira. Piaget para principiantes. 5.ed. São Paulo: Summus Editorial, 1980.

MAN, John. A historia do alfabeto: como 26 letras transformaram o mundo ocidental. Trad. Edith Zonenschain. Rio de Janeiro: Ediouro, 2002.

MARX, Karl; ENGELS, Friedrich. Manifesto de la Komunista Partio. Trad. Detlev Blanke. Moscou: Progresso, 1990.

SARAMAGO, José. Manual de pintura e caligrafia. Porto: Lello \& Irmão, 1991a. v.2

SARAMAGO, José. Os poemas possiveis. Porto: Lello \& Irmão, 1991b. v.1 